\section{PDMS Substrates with tunable stiffness for cardiac mechanobiology investigation: A nanoindentation study}

Gianpaolo Serino,1,2 Andrea T. Lugas, 1,2

Giacomo Bernava, ${ }^{3}$ Sara Ragazzini, ${ }^{3}$

Stefano Gabetti,1,2 Mara Terzini,1,2

Umberto Morbiducci, ${ }^{1,2}$ Alberto

Audenino, 1,2 Maurizio Pesce, ${ }^{3}$

Diana Massai ${ }^{1,2}$

1PolitoBIOMed Lab, Dept. of

Mechanical and Aerospace Engineering,

Politecnico di Torino, Torino;

2Interuniversity Center for the

Promotion of the 3Rs Principles in

Teaching and Research; ${ }^{3}$ Centro

Cardiologico Monzino, Milan, Italy

\begin{abstract}
Micromechanical characterization by nanoindentation of PDMS substrates for cardiac mechanobiology studies.
\end{abstract}

\section{Introduction}

Mechanical cues play a continuous, crucial regulatory role in growth, maintenance, and pathophysiology of cardiac tissue. ${ }^{1,2}$ In particular, cardiac cells can translate changes in biophysical characteristics of the surrounding matrix, such as stiffness, into intracellular activation cascades with consequent evolution toward proinflammatory/pro-fibrotic phenotypes. . $^{3,4}$ Thus, for studying in vitro cardiac cell mechanobiology, it is crucial to use substrates that mimic the mechanical properties of the native physiological or pathological environment. Here, specific Polydimethylsiloxane (PDMS) blends with tunable stiffness, 5 to be used as model substrates for cardiac mechanobiology investigations, were prepared. By allowing investigations at typical cell-length scales 6,7 and applying small forces suitable for soft materials, nanoindentation was adopted to mechanically characterize PDMS blends in physiological conditions (wet conditions, $\left.37^{\circ} \mathrm{C}\right)$.

\section{Materials and Methods}

PDMS substrates with tunable stiffness were prepared using pure Sylgard 184 and Sylgard 527 (Dow Corning, USA). Five dif- ferent Sylgard mass ratios 184:527 (1:10, $1: 20,1: 30,1: 50,1: 100)$ were blended. PDMS blends were poured into $50 \mathrm{~mm}$ diameter petri dishes (cured at $65^{\circ} \mathrm{C}$ ) to create $\sim 3 \mathrm{~mm}$ thick films for mechanical testing. The procedure was repeated in three different days producing three lots (seven specimens per lot) for checking the manufacturing reproducibility. Indentation of the specimens, immersed in demineralized water at room temperature (RT) or at $37^{\circ} \mathrm{C}$, was performed in displacement-control (indentation depth $=2 \mu \mathrm{m}$, cantilever stiffness $=4.4 \mathrm{~N} / \mathrm{m}$ for Sylgard 184, $0.5 \mathrm{~N} / \mathrm{m}$ for the other specimens) using the PIUMA nanoindenter (Optics11, NL), which automatically provided the load-indentation curves and their respective elastic modulus (E) values (Hertz model fitting). Each PDMS specimen was indented in three different regions performing, in each region, indentation matrices of 25 points equally spaced of $50 \mu \mathrm{m}$. Three different indentation rates $(\mathrm{v} 1=1 \mu \mathrm{m} / \mathrm{s}, \mathrm{v} 2=10 \mu \mathrm{m} / \mathrm{s}, \mathrm{v} 3=$ $50 \mu \mathrm{m} / \mathrm{s}$ ) were adopted. In parallel, preliminary indentation tests were performed on a sample of bovine myocardium. The specimen $\left(\sim 3 \times 3 \times 0.5 \mathrm{~cm}^{3}\right)$, immersed in demineralized water at $37^{\circ} \mathrm{C}$, was indented in a central region $(5 \times 5$ points, step size $=100 \mu \mathrm{m})$ in displacement-control (indentation depth $=4.5 \mu \mathrm{m}$, cantilever stiffness $=0.5 \mathrm{~N} / \mathrm{m}$, indentation rate $=2 \mu \mathrm{m} / \mathrm{s}$ ). Statistical analysis of variance was performed to assess the impact of temperature and, indentation rate on derived $E$ values $(p<0.05)$.

\section{Results}

No statistical differences emerged among PDMS lots in terms of elastic modulus, proving the reproducibility of the

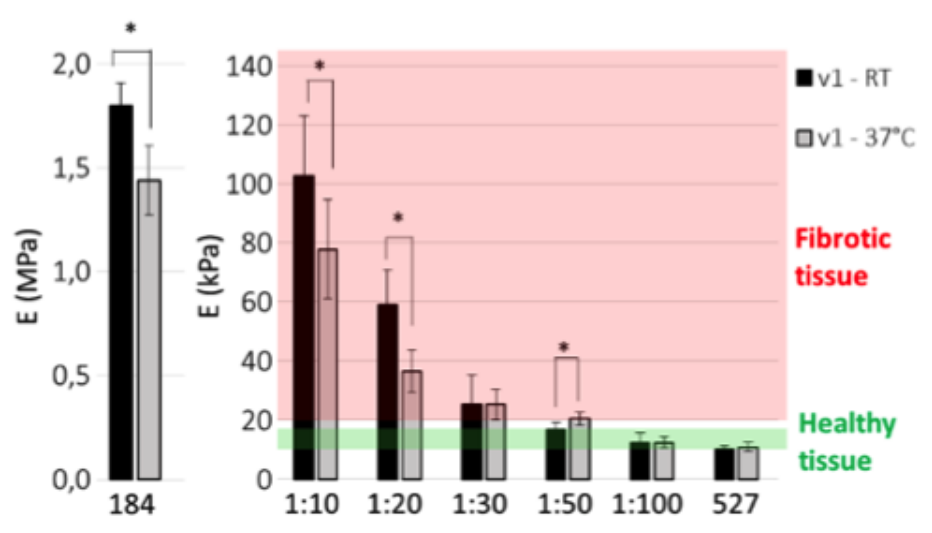

Figure 1. Average E values measured for all PDMS specimens at $\mathrm{RT}$ and at $37^{\circ} \mathrm{C}(\mathrm{v} 1=1$ $\mu \mathrm{m} / \mathrm{s})$. The ranges of $\mathrm{E}$ values reported in literature for healthy (10-15 $\mathrm{kPa}$, green band) and fibrotic $\left(20-100 \mathrm{kPa}\right.$, red band) cardiac tissue are shown $\left({ }^{*} \mathrm{p}<0.05\right) .8$
Correspondence: Gianpaolo Serino, PolitoBIOMed Lab, Departement of Mechanical and Aerospace Engineering, Politecnico di Torino, Turin; Interuniversity Center for the Promotion of the 3Rs Principles in Teaching and Research, Italy.

E-mail: gianpaolo.serino@polito.it

Key words: Nanoindentation; mechanobiology; PDMS; cardiac tissue; cardiac fibrosis.

Disclosures: The authors have nothing to disclose.

Conference presentation: This paper was presented at the Third Centro 3R Annual Meeting - L'era delle 3R: modelli in silico, in vitro e in vivo per promuovere la ricerca traslazionale 30 September - 1 October 2021, Evento online organizzato dal Politecnico di Torino.

Received for publication: 9 July 2021.

Accepted for publication: 7 September 2021.

This work is licensed under a Creative Commons Attribution NonCommercial 4.0 License (CC BY-NC 4.0).

(C) Copyright: the Author(s), 2021

Licensee PAGEPress, Italy

Biomedical Science and Engineering 2021; 4(s1):192 doi:10.4081/bse.2021.192

manufacturing. Considering specimens with decreasing mass ratio of Sylgard 184 with respect to Sylgard 527, the average of the measured $\mathrm{E}$ values (setting v1) ranged from $1.80 \pm 0.09 \mathrm{MPa}$ to $10.25 \pm 2.76 \mathrm{kPa}$ when tested at RT, and from $1.44 \pm 0.13 \mathrm{MPa}$ to $10.87 \pm 1.47 \mathrm{kPa}$ when tested at $37^{\circ} \mathrm{C}$ (Fig. 1). Interestingly, 1:10, 1:20 and, 1:30 blends matched the E values of fibrotic tissue (20$100 \mathrm{kPa}$ ), while $1: 50$ and 1:100 blends matched the $\mathrm{E}$ values of healthy cardiac tissue $(10-15 \mathrm{kPa}){ }^{8}$ Pure Sylgard 527 showed 
E values close to the lowest limit of the characteristic $\mathrm{E}$ values of healthy cardiac tissue. By increasing the indentation rate, the measured $E$ values significantly increased, confirming the viscoelastic behavior of PDMS.

Furthermore, the statistical analysis indicated that the mechanical properties of the blends were less influenced by temperature increasing the quantity of Sylgard 527. As regards preliminary tests on bovine myocardium, the average of the measured $\mathrm{E}$ values $(11.76 \pm 2.81 \mathrm{kPa})$ was in agreement with literature data for normal heart muscle.

\section{Discussion and Conclusions}

The findings support the use of specific PDMS blends as model substrates for mimicking in vitro the mechanical properties of physiological or pathological cardiac tissue. Interestingly, it emerged that the testing temperature has an effect on PDMS mechanical properties, in particular for blends stiffer than $30 \mathrm{kPa}$.

To our knowledge, this is the first sys- tematic attempt to characterize at typical cell-length scale and in physiological conditions the mechanical properties of specific PDMS blends for mechanobiology applications, in view of future biological tests aimed at elucidating the role of substrate stiffness in cardiac mechanobiology mechanisms.

\section{References}

1. Zhu R, Blazeski A, Poon, E. et al. Physical developmental cues for the maturation of human pluripotent stem cell-derived cardiomyocytes. Stem Cell Res Ther 2014;5:117.

2. Pesce M, Messina E, Chimenti I, Beltrami AP. Cardiac mechanoperception: a life-long story from early beats to aging and failure. Stem Cells Dev 2017;26:77-90.

3. Pesce M, Santoro R. Feeling the right force: How to contextualize the cell mechanical behavior in physiologic turnover and pathologic evolution of the cardiovascular system. Pharmacol Ther
2017;171:75-82.

4. Garoffolo G, Pesce M. Mechanotransduction in the Cardiovascular System: From Developmental Origins to Homeostasis and Pathology. Cells 2019;8:1607.

5. Palchesko RN, Zhang L, Sun Y, Feinberg AW. Development of polydimethylsiloxane substrates with tunable elastic modulus to study cell mechanobiology in muscle and nerve. PLoS One 2012;7:e51499.

6. Serino G, Bignardi C, Boccafoschi C, et al., Collagen cross-linker effect on the mechanical properties of the radicular hybrid layer in restorative dentistry: a nanoindentation study. Wit Transaction Engin Sci 2019;124:195-203.

7. Zanetti EM, Serino G, Audenino AL, Bignardi C. Artificial turf pitches and synthetic grass: macro and nano friction properties. IJMET 2018;9: 832-9.

8. van Putten S, Shafieyan Y, Hinz B. Mechanical control of cardiac myofibroblasts. J Mol Cell Cardiol 2016;93:133-42. 